\title{
Advancing theory development: exploring the leadership-climate relationship as a mechanism of the implementation of cultural competence
}

\author{
Erick G. Guerrero ${ }^{1,2^{*}} \mathbb{D}$, Karissa Fenwick ${ }^{1}$ and Yinfei Kong ${ }^{3}$
}

\begin{abstract}
Background: Leadership style and specific organizational climates have emerged as critical mechanisms to implement targeted practices in organizations. Drawing from relevant theories, we propose that climate for implementation of cultural competence reflects how transformational leadership may enhance the organizational implementation of culturally responsive practices in health care organizations.

Methods: Using multilevel data from 427 employees embedded in 112 addiction treatment programs collected in 2013, confirmatory factor analysis showed adequate fit statistics for our measure of climate for implementation of cultural competence (Cronbach's alpha $=.88$ ) and three outcomes: knowledge (Cronbach's alpha $=.88)$, services (Cronbach's alpha $=.86)$, and personnel (Cronbach's alpha $=.86)$ practices.

Results: Results from multilevel path analyses indicate a positive relationship between employee perceptions of transformational leadership and climate for implementation of cultural competence (standardized indirect effect $=.057$, bootstrap $p<.001$ ). We also found a positive indirect effect between transformational leadership and each of the culturally competent practices: knowledge (standardized indirect effect $=.006$, bootstrap $p=.004$ ), services (standardized indirect effect $=.019$, bootstrap $p<.001$ ), and personnel (standardized indirect effect $=.014$, bootstrap $p=.005)$.

Conclusions: Findings contribute to implementation science. They build on leadership theory and offer evidence of the mediating role of climate in the implementation of cultural competence in addiction health service organizations.
\end{abstract}

Keywords: Transformational leadership, Organizational climate, Cultural competence, Implementation

\section{Background}

Health care organizations require leadership to implement practices that are effective and culturally responsive to the increasing racial and ethnic diversity of the US population. To address the well-established disparities between health outcomes of racial and ethnic minorities compared to Whites, federal and private institutions have supported the implementation of culturally competent practices $[1,2]$. Cultural competence refers

\footnotetext{
*Correspondence: erickgue@usc.edu

'Suzanne Dworak-Peck School of Social Work, University of Southern

California, 655 West 34th Street, Los Angeles, CA 90089, USA

${ }^{2}$ Marshall School of Business, University of Southern California, 655 West 34th

Street, Los Angeles, CA 90089, USA

Full list of author information is available at the end of the article
}

to the recognition and responsiveness of organizations to the service needs of culturally and linguistically diverse populations and aims to improve health care quality, engage racial and ethnic minority clients in care, and reduce outcome disparities [3-6]. Some culturally responsive practices, such as language and racial and ethnic provider-client matching, translating materials, and using cultural stories to engage clients in services, have robust associations with health outcomes [3-6]. Yet culturally responsive practices, which are consistent with Klein and Sorra's [7] theory of innovation implementation, can be considered an innovation because their implementation require active and coordinated use by many organizational members and they are not 
routinely applied in health care settings. Efforts to systematically examine the drivers of implementation of innovative culturally responsive practices in health care [8] and addiction health services $[9,10]$ are limited.

Leadership is a key factor associated with implementation of service innovations such as cultural competence, given that organizational leaders are generally responsible for overseeing the implementation process [11]. Theory suggests that leadership affects implementation both directly and indirectly by shaping the organizational context, which then influences employee behaviors [12]. Developing research shows that leaders' communication and prioritization of new norms and expectations (e.g., safety) influence employee adoption of those norms and endorsement of congruent practices (e.g., safer work practices), generally referred to as organizational climate. The organizational climate supports and encourages employees in implementing a new practice [13]. This leader-climate-practice mechanism has been examined in the context of implementation of industrial safety [14], corporate customer services [15], and evidence-based health care practices [16]. However, it is critical to examine the extent to which this mechanism applies to cultural competence. Although commonly endorsed in health care services, cultural competence requires creative thinking to implement key cultural aspects (e.g., familismo, language, context) that may affect client outcomes $[1,2]$. Understanding the role of leadership and implementation climate in the uptake of cultural competence in health care is critical to improve clients' response to treatment, particularly in substance use disorder treatment programs whose unique structure as generally small programs with an average of five to six employees allows managing leaders to have direct and daily interactions with employees.

\section{Theoretical framework}

One of the most influential leadership styles described in the management literature is transformational leadership $[17,18]$. Transformational leadership is a leader's ability to inspire others to follow a particular course of action and perform beyond previous levels [19, 20]. Transformational leaders consider the unique talents of each staff member or employee (these terms are used interchangeably in this paper), give specific feedback to each staff member based on his or her needs, stimulate new ways of solving problems, and create a shared sense of purpose among all staff members $[19,21]$. Transformational leadership is thought to be transmitted through a leader's expression of his or her values and goals and selection, modeling, and communication of relevant information, which staff members use when weighing options and making decisions [16, 22, 23].
Transformational leadership has been shown to play a role in the adoption and implementation of innovations in health care [24-26]. Leadership style influences multiple organizational processes involved in delivery of innovative practices [11]. For instance, leaders initiate adoption decisions, develop strategic goals and activities supporting innovation implementation, secure necessary resources, build organizational capacity for change, scan the internal and external contexts, and provide performance feedback to the staff $[9,27,28]$. One of the most important ways in which leaders affect delivery of innovative practices is by creating an organizational context conducive to implementing new practices. In particular, leaders positively or negatively contribute to the creation, development, and sustainment of an organizational climate that fosters employee attitudes and behaviors that support innovative practice use [25, $29,30]$. A leader in the current study refers to executive or upper level directors who oversee the overall operation of treatment programs and whose transformational style may influence employees, such as middle managers (i.e., supervisors) and counselors.

\section{Organizational climate}

Organizational climate can be understood as employees' shared perceptions of procedures, practices, and behaviors that are rewarded and supported by management with a specific purpose [31]. When the purpose involves implementing practices that respond to client's native cultural norms and values, language, and history, the resultant shared perceptions can be defined as climate for implementation of cultural competence.

Many definitions of climates have emerged. These definitions of organizational climates seem to differ based on the language used to capture the level of agreement among employees regarding the implicit and or explicit priorities of the organization. These priorities are generally communicated by managers through organizational policies, procedures, and practices, leading to employees' shared notion of "the way things are done around here" [32, 33]. Hence, measurement of this conceptualization has focused on what is expected, supported, promoted, rewarded, and punished in the work context [34, 35].

Moreover, organizational climate can be conceptualized and measure either as a singular, molar climate (e.g., shared perceptions of organizational policies and procedures) that influences nearly all activities in an organization or as multiple simultaneous focused climates (shared perceptions of a direct manager's priorities through rewards and support of employees' specific behaviors and attitudes) [35]. Recent climate research suggested that a molar climate may lay the groundwork for focused climates, which then serve as more proximal predictors of outcomes [36, 37]. As a result, the latest 
research on climate has focused on the development of specific climates for desired organizational goals (such as customer service and safety) or processes (such as creativity) [15]. Focused climates consist of the components of the organizational environment that are most influential in orienting employee behavior toward the outcome of interest. The development of these focused climates improves prediction and understanding of targeted outcomes and makes the climate construct more practically relevant to managers seeking to enhance performance in specific areas [15, 37]. Assessment of focused climates using employees' shared perceptions of the consistency among policies, procedures, and practices-basically "leader's words and actions" in prioritizing implementation of a new practice-may improve understanding of climate as a mechanism that influences employees' attitudes and behaviors [35].

Empirical research has supported the association between many specific climates and their targeted outcomes. Safety climate is associated with decreased accidents [38, 39], service climate is associated with greater customer satisfaction [40, 41], climate for creativity is associated with creative performance [42], and climate for innovation is associated with greater innovative behavior [43]. In this study, implementation climate for cultural competence can be defined as employees' shared perceptions of their program supervisors' priority to implement culturally responsive practices through expectations, support, promotions, rewards, and punishments $[34,35]$. In a strong implementation climate, employees perceive new practices as a priority rather than a distraction or disruption [7, 44]. Several studies have found a positive association between implementation climate and implementation effectiveness, although empirical studies of implementation climate are limited [45-47].

Implementation climate can be further tailored to refer to implementation of new knowledge, practices, or processes as promoted, rewarded, and expected by direct supervisors and perceived by employees. For example, in a strong climate for implementation of cultural competence, employees perceive that the adoption, implementation, and use of culturally competent knowledge, services, and practices is expected, rewarded, and supported by management [48].

\section{Organizational climate as a mediator}

Leading climate scholars [35, 37, 49] have advised researchers to examine the relationships among leadership, climate, and outcomes in more depth. They recommended exploring how leaders create and maintain climate and how climate mediates the relationship between leadership and outcomes.

Understanding the leader-climate-practice mechanism necessitates a theoretical explanation of how leaders influence focused climates. Leaders may shape organizational climate through a social learning process in which staff members repeatedly interact with and observe their leader to interpret organizational priorities $[29,50]$. Leaders convey the importance of various tasks in an organization through implicit and explicit communication of priorities [51, 52]. Through their behavior and interactions with employees, they communicate the value of each task and their evaluation of tasks in comparison with one another. Leaders communicate their priorities in several ways. They develop strategic goals for the organization, disseminate information, monitor and supervise staff activities, model desired behavior, and reward staff behavior in line with the prioritized behavior or outcome [53-55]. These activities occur more frequently or intensely for prioritized behaviors or outcomes in comparison to those that are not prioritized.

Three main attributes characterize the relationship between leadership behavior patterns and communicated priorities [56]. Pattern orientation refers to communicating a particular priority relative to other competing interests, pattern variability refers to the consistency of leader behavior in communicating a particular priority over time and among different staff members, and pattern simplicity is the number of contingencies that influence a priority. Leaders who prioritize implementation of cultural competence may communicate this priority by developing strategic goals and plans supporting culturally competent practices, allocating resources for culturally competent services, and providing supervision and coaching to build culturally competent knowledge. In addition, they may persevere in the face of challenges to implementation and reward employees based on provision of culturally competent services [27, 28, 57]. By communicating their expectations and priorities in these ways, leaders develop, support, and perpetuate an organizational climate [56]. See Fig. 1.

The climate-practice relationship is based on climate's role as a guide and sense-making mechanism that influences employees' attitudes and behaviors [58]. Employees interpret their environment, and climate acts as a critical determinant that influences these interpretations $[59,60]$.

\section{Overview of the current research}

We examined the organizational processes driving implementation of culturally competent knowledge, practices, and services. We focused on the organizational climate for implementation of cultural competence (employees' shared perceptions of middle managers' priorities, expectations and rewards to implement cultural competence) to explore the extent to which it enhances executive leaders' transformational leadership in the implementation of significant culturally competent practices in addiction health services. Executive or program 


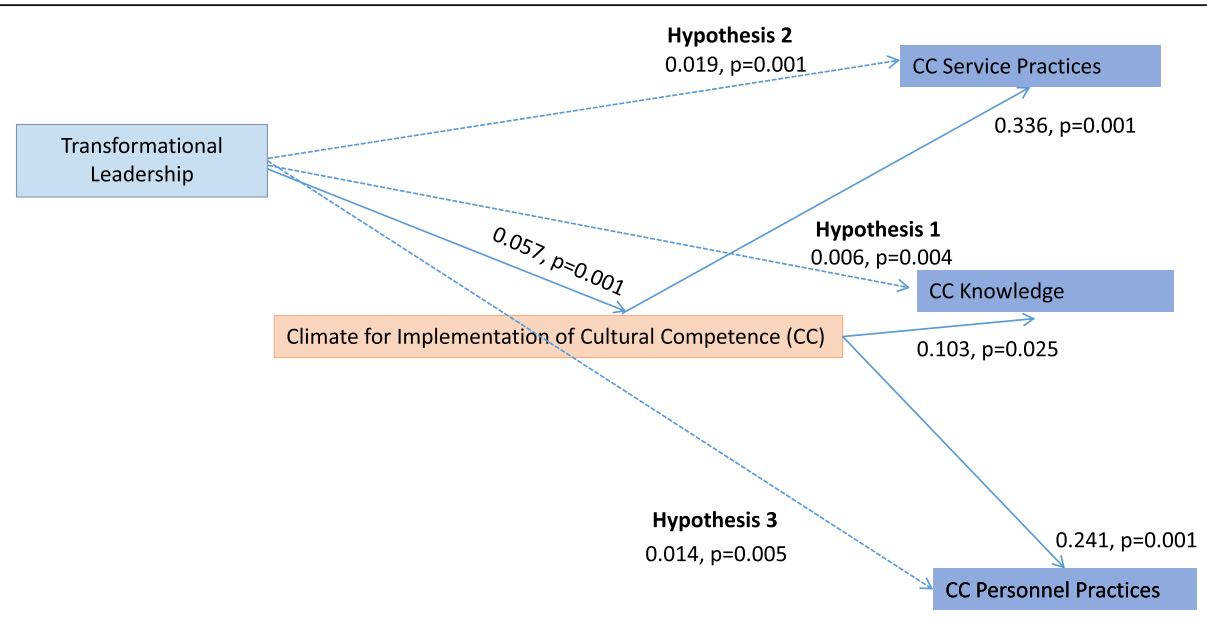

Fig. 1 Path analysis of transformational leadership, climate for implementation of cultural competence, and three culturally competent practices. Note. Control variables include program funding, licensure, and professionalism

directors are referred to here as executive or upper level leaders, whereas clinical supervisors are referred to as middle managers. Our hypotheses are as follows:

Hypothesis 1

Transformational leadership will be positively and indirectly related to the implementation of culturally competent knowledge through climate for implementation of cultural competence.

Hypothesis 2

Transformational leadership will be positively and indirectly related to the implementation of culturally competent service practices through climate for implementation of cultural competence.

Hypothesis 3

Transformational leadership will be positively and indirectly related to the implementation of culturally competent personnel practices through climate for implementation of cultural competence.

\section{Methods}

\section{Background and context}

This study used data from a larger study featuring a sampling frame of 408 addiction health services programs funded by a public health department in Los Angeles County between July 1, 2013, and December 31, 2013. Data for the current study came from the second wave of the larger study, during which all relevant variables were introduced. The initial sampling procedure involved a random selection of 147 outpatient programs located in communities with a population composition of $40 \%$ or more Latino or African American residents or both in the study region. Data collection for this wave included information from an average of three directservice providers per program (one manager and two counselors). Only programs with at least two respondents, a counselor, and a manager (either director or supervisor) were included in the analysis. Most programs had an executive or upper level director, a middle manager (e.g., supervisor), and a counselor. Only 5\% of programs had one manager with dual directorial and supervisory responsibilities and who reported on both program funding and regulation, as well as on the transformational leadership of their executive director. Data collectors obtained staff rosters to select at random respondents within programs; overall, the sample composition was $25.4 \%$ directors, $15.7 \%$ supervisors, and $58.9 \%$ counselors.

Considering eligible and still operating programs, the final analytic sample featured 112 programs $(92 \%$ response rate) and 427 individual participants. The 35 programs not included in this wave did not differ from the original analytic sample in terms of main independent variables, such as leadership style (transformational) and cultural competence $(p>.05)$.

A treatment program was defined as an outpatient site managed as a standalone program or by a parent organization generally situated at a different location. The average age of participants in the sample was 46 years, and $34 \%$ of participants were men. Most managers were African American (45\%) or Latino (32\%), as were counselors (43 and $47 \%$, respectively).

Our power analysis suggest that we would have $80 \%$ power to detect a medium effect size, which is associated with a Pearson's correlation of .24, when considering 99 programs and 15 variables in the statistical regression analysis [61]. To increase the validity of the survey measures, we conducted in vivo observations and reviewed printed materials available at each provider site (e.g., brochures, group activities, posted signs). For example, for each dependent variable (culturally competent practices), we used a matrix (Excel sheet) with key program features to cross-check the consistency of staff reports 
on survey measures. All measures were responded to by supervisors and counselors except for regulation, public funding, and professionalization, which were responded to by upper level managers (i.e., directors) or managers with both supervisory and directorial responsibilities.

\section{Dependent variables}

The organizational cultural competence survey measures were adapted from the Cultural Competence SelfAssessment Questionnaire [6]. This 57-item measure is composed of six subscales assessing culturally competent practices: (a) knowledge of, (b) outreach to, and (c) personal involvement in racial and ethnic minority communities; (d) development of resources and linkages to serve racial and ethnic minorities; (e) development of policies and procedures to effectively respond to the service needs of racial and ethnic minority patients; and (f) hiring and retention of employees with racial and ethnic minority backgrounds (for a full description of items, see Mason [6]). We used the 57 items to empirically develop three critical subscales as suggested by the literature: knowledge (eight items, e.g., Do you know the prevailing beliefs, customs, norms, and values of Latinos in your service area?); service practices (nine items, e.g., Does your agency utilize interpreters to work with limited English-proficient Latinos?); and personnel practices (nine items, e.g., Does your agency utilize interpreters to work with limited English-proficient Latinos). Responses were rated on a 4-point Likert scale $(1=$ not at all to $4=$ often) and averaged to create total scores for each subscale. Higher scores indicated higher levels of cultural competence in each subdomain, as perceived by supervisors and counselors. Confirmatory factor analysis was conducted to validate these measures (see Table 1 for descriptive statistics; confirmatory factor analysis results are reported in Table 2).

\section{Independent variables}

Our main independent variables were leadership style (transformational) and climate for the implementation of cultural competence. A 7-item measure assessed transformational leadership among executive or upper level leaders (i.e., agency directors) [62]. This short version has been used in several studies on staff's perception of directors' transformational leadership in health care services [62-65]. Each director's leadership was rated by clinical supervisors and counselors on a 5 -point scale (1 $=$ strongly disagree to $5=$ strongly agree) and scores were totaled as suggested by the measure's authors [62]. Higher scores represented higher transformational leadership capacity as perceived by clinical supervisors and counselors. Cronbach's alpha for transformational leadership capacity was .92 .
We measured climate for the implementation of cultural competence using six items. The development of these items was informed by other climate measures in safety [38], customer satisfaction [41], and innovative behavior [43]. Climate is generally enforced through middle managers' communicated priorities, rewards, and expectations [36, 56]. Altogether, the leadership-climate-practice mechanism is supported by empirical evidence showing that organizational climate acts as a mediator between leadership and a variety of outcomes, including innovation implementation behavior [25, 30, $59,60]$. Our measure of climate was rated by clinical supervisors and staff members on a 5 -point scale $(1=$ not at all to $5=$ very well) and scores were aggregated by program and totaled as suggested by authors of climate measures [35, 38, 49]. Higher scores represented stronger employee perceptions that the implementation of culturally competent practices was promoted, rewarded,

Table 1 Descriptive statistics from 427 participants nested in 112 programs

$M(\mathrm{SD})$ or \% Range

Participant demographics

Age $46.6(11.7) \quad 19-75$

Race and ethnicity

Latino $\quad 40.1$

African American $\quad 27.6$

White $\quad 21.6$

Other $\quad 10.1$

Position

Director 25.3

Supervisor $\quad 15.7$

Counselor $\quad 58.8$

Education

High school or lower $\quad 5.9$

College $\quad 56.4$

Graduate degree $\quad 32.3$

Program measures

Transformational leadership $\quad 39.4(7.5) \quad 10-50$

Climate for implementation of cultural $\quad 3.4(0.85) \quad 1-5$ competence

Knowledge

Personnel practices

$2.9(0.57) \quad 1-4$

Service practices

$2.6(0.74) \quad 1-4$

$2.4(0.87) \quad 1-4$

Control variables

Percentage of public funding $\quad 67.9$

Licensing $\quad 96.3$

Professional accreditation (Joint Commission) $\quad 32.7$

Professionalization (\% of staff with $21.6(18.3) \quad 0-75$ graduate degree) 
Table 2 Confirmatory factor analysis of culturally competent practices (knowledge, service, and personnel)

\begin{tabular}{|c|c|c|c|c|c|}
\hline & Obs & $\begin{array}{l}\text { Item } \\
\text { test }\end{array}$ & $\begin{array}{l}\text { Item } \\
\text { rest }\end{array}$ & $\begin{array}{l}\text { Interitem } \\
\text { covariance }\end{array}$ & a \\
\hline \multicolumn{6}{|l|}{ Knowledge } \\
\hline How well are you able to describe differences within various Latino or Hispanic groups? & 424 & .701 & .557 & .292 & .888 \\
\hline How well are you able to describe the strengths of Latino groups in your service area? & 427 & .807 & .716 & .277 & .861 \\
\hline How well are you able to describe the social problems of Latino groups in your community? & 425 & .866 & .804 & .270 & .849 \\
\hline Do you know the prevailing beliefs, customs, norms, and values of Latinos in your service area? & 426 & .834 & .749 & .267 & .856 \\
\hline Do you know the social service needs of Latinos that go unaddressed by the formal social service system? & 421 & .829 & .736 & .261 & .857 \\
\hline Do you know how the causes of mental illnesses are viewed by Latino groups in your area? & 430 & .773 & .656 & .274 & .870 \\
\hline Full scale & & & & .274 & .884 \\
\hline \multicolumn{6}{|l|}{ Service practices } \\
\hline Does your agency use Latino-specific assessment instruments for diagnosis? & 294 & .737 & .647 & .613 & .832 \\
\hline Does your agency use Latino culture-specific treatment approaches? & 290 & .761 & .683 & .605 & .830 \\
\hline Does your agency envision community empowerment as a treatment goal? & 291 & .745 & .660 & .602 & .831 \\
\hline Does your agency review case practice on a regular basis to determine relevancy to clients of color? & 288 & .749 & .659 & .594 & .831 \\
\hline Does your agency provide or facilitate child care? & 298 & .688 & .569 & .612 & .842 \\
\hline Does your agency provide or facilitate transportation (e.g., bus tickets, ride sharing)? & 296 & .627 & .495 & .632 & .850 \\
\hline Does your agency include clients' families and community in services? & 298 & .734 & .637 & .599 & .833 \\
\hline Does your agency translate agency materials into Spanish? & 302 & .634 & .520 & .640 & .846 \\
\hline Does your agency offer payment arrangements for indigent or low-income clients? & 296 & .499 & .361 & .688 & .860 \\
\hline Full scale & & & & .621 & .855 \\
\hline \multicolumn{6}{|l|}{ Personnel practices } \\
\hline Does staff utilize cultural consultants who can help them work more effectively? & 422 & .516 & .375 & .486 & .863 \\
\hline Does your agency provide training that help staff work with Latinos? & 419 & .570 & .445 & .475 & .856 \\
\hline Does your agency utilize interpreters to work with limited English-proficient Latinos? & 418 & .503 & .346 & .485 & .869 \\
\hline In your program, are there Latinos represented in managerial and administrative positions? & 424 & .759 & .670 & .421 & .834 \\
\hline In your program, are there Latinos represented in direct-service positions? & 426 & .709 & .620 & .444 & .840 \\
\hline In your program, are there Latinos represented in administrative support positions? & 421 & .770 & .691 & .425 & .832 \\
\hline In your program, are there Latinos represented in board positions? & 413 & .789 & .712 & .418 & .830 \\
\hline In your program, are there Latinos represented in agency consultants? & 410 & .816 & .750 & .416 & .827 \\
\hline In your program, are there Latinos represented in subcontractors? & 400 & .711 & .711 & .420 & .831 \\
\hline Full scale & & & & .443 & .858 \\
\hline
\end{tabular}

Obs observations

and expected by their manager. A sample item of a promoted practice is: "Supervisor prioritizes enhancing the staff's cultural competence by helping resolve crosscultural issues with clients." An item measuring a rewarded practice include: "Supervisor provides incentives to the staff to become linguistically and culturally responsive, despite investment of time and resources." An item measuring an expected practice is: "Supervisor has emphasized the importance of translation of material and development of policies and procedures to respond to clients with limited English proficiency, despite her or his other multiple responsibilities." We measured the internal consistency of survey items to determine their overall reliability as a measure. Cronbach's alpha for this leadership measure was .88 .

\section{Control variables}

These variables included regulation, public funding, and professionalization. Please refer to Table 1 for a full list of variables. We assessed regulation by determining whether each program had a state license and accreditation by the Joint Commission. We also included a measure of percentage of public revenue in each program's budget; professionalization was measured using the percentage of staff members with a graduate degree. 
These factors are associated with implementation of new practices in addiction health services $[26,63,66]$.

\section{Statistical analyses}

Studies have shown that leadership across organizations is nested in different settings [67], requiring adjustment for context to properly evaluate leadership influence. In this case, hierarchical linear modeling was needed to analyze nested data [68]. In our study, we accounted for control variables, program funding, license, professional accreditation, and professionalism, which play a role in the implementation and delivery of new practices [26, 69]. The hierarchical linear modeling analysis considered staff members at level 1 to be nested in programs at level 2.

As reported in other studies using these data [65], because we assumed data was missing at random, we relied on maximum likelihood estimation in multivariate regressions, which allows us to obtain unbiased estimate parameters [70]. Our highest rate of missing data for any given variable was $4 \%$. This procedure was conducted in Stata/SE version 12.

Confirmatory factor analysis was conducted in Stata/ SE using maximum likelihood estimation procedures as well to validate our measure of climate for the implementation of cultural competence consistent with other organizational level research [71]. The results of the analysis are shown in Tables 2 and 3.

To validate our measure of climate for the implementation of cultural competence and determine whether it is a unit-level construct, we relied on established methodologies applied to organizational constructs following the approach used by Glisson and James ([72], p. 780). First, we used 'confirmatory factor analysis to determine whether responses justify a latent concept of climate for implementation of cultural competence. Second, we conducted a within-group consistency analysis using $r_{\mathrm{WG}}$ to test whether members of each of the 112 treatment programs agreed with one another in their responses to the leadership scales [73]. This approach is common in organizational research to justify whether individual level responses can be aggregated and represent program measures. Third, we conducted between-group analysis using eta squared via analysis of variance and intraclass correlation coefficient via hierarchical linear modeling to test between-group differences among program staff members for each construct.' [74].

Finally, we used hierarchical linear modeling path analyses in Stata version 13. We selected a random-intercepts model to estimate relationships between individual-level measures nested in programs $[68,75]$. Specifically, we ran three regression models, one per outcome, while controlling for program regulation, funding, and professionalism to estimate the contribution of transformational leadership
Table 3 Psychometric properties of climate for the implementation of cultural competence

\begin{tabular}{|c|c|c|c|c|c|}
\hline Item & Obs & $M(\mathrm{SD})$ & ICC & Awg & $a$ \\
\hline $\begin{array}{l}\text { Item 1: Supervisor provides incentives } \\
\text { to the staff to become linguistically } \\
\text { and culturally responsive, despite } \\
\text { investment of time and resources }\end{array}$ & 237 & $\begin{array}{l}2.916 \\
(1.121)\end{array}$ & & $\begin{array}{l}0.596 \\
(0.434)\end{array}$ & .885 \\
\hline $\begin{array}{l}\text { Item 2: Supervisor creates } \\
\text { opportunities to talk to the staff about } \\
\text { ways to respond to clients' cultural } \\
\text { and linguistic service needs despite his } \\
\text { or her other administrative } \\
\text { responsibilities (e.g., documentation } \\
\text { and billing) }\end{array}$ & 239 & $\begin{array}{l}3.410 \\
(1.045)\end{array}$ & & $\begin{array}{l}0.665 \\
(0.285)\end{array}$ & .847 \\
\hline $\begin{array}{l}\text { Item 3: Supervisor provides clear } \\
\text { guidance about how to respond to } \\
\text { clients' cross-cultural issues despite } \\
\text { busy schedule }\end{array}$ & 241 & $\begin{array}{l}3.577 \\
(1.014)\end{array}$ & & $\begin{array}{l}0.602 \\
(0.410)\end{array}$ & .829 \\
\hline $\begin{array}{l}\text { Item 4: Supervisor has emphasized the } \\
\text { importance of translation of material } \\
\text { and development of policies and } \\
\text { procedures to respond to clients with } \\
\text { limited English proficiency, despite her } \\
\text { or his other multiple responsibilities }\end{array}$ & 238 & $\begin{array}{l}3.378 \\
(1.043)\end{array}$ & & $\begin{array}{l}0.540 \\
(0.449)\end{array}$ & .845 \\
\hline $\begin{array}{l}\text { Item 5: Supervisor prioritizes } \\
\text { enhancing the staff's cultural } \\
\text { competence by helping resolve } \\
\text { cross-cultural issues with clients }\end{array}$ & 240 & $\begin{array}{l}3.546 \\
(0.967)\end{array}$ & & $\begin{array}{l}0.636 \\
(0.453)\end{array}$ & .850 \\
\hline Test scale & & & .07 & $\begin{array}{l}0.774 \\
(0.221)\end{array}$ & .878 \\
\hline
\end{tabular}

to cultural competence outcomes via climate for the implementation of cultural competence. Our analyses used individual measures while controlling for staff measures embedded in programs. The path model was implemented using the GSEM builder in Stata/SE version 12. This model studied both the direct effects of the causal variable (i.e., transformational leadership) on the outcome (culturally responsive practices) and its indirect effects through the mediator (implementation climate). These analyses respond to the main research question: To what extent does climate for implementation of cultural competence play a mediating role in the relationship between transformational leadership and program implementation of cultural competence (knowledge, services, and personnel practices)?

\section{Results}

We conducted confirmatory factor analysis to validate our outcome measures of cultural competence and mediator variable of climate for implementation of cultural competence. The 57-item measure of cultural competence [6] resulted in three dimensions of organizational cultural competence-knowledge (six items), service practices (nine items), and personnel practices (nine items)-that are consistent with theoretical and empirical descriptions of this concept [4-6]. See Table 2. 


\section{Cultural competence: knowledge}

We excluded two of the original eight items because they had item-rest correlations less than .50 , resulting in a six-item scale. As shown in Table 2, Cronbach's alpha for this scale was very high (.88), with all items contributing in the same direction and item-test and item-rest correlations greater than .56. Therefore, for ease of interpretation, we averaged the six items to create a new aggregate measure.

\section{Cultural competence: service practices}

After inconsistent results, we reduced the original 14 items to nine that contributed in the same direction and had consistent levels of item-test and item-rest correlations, with only one less than .57. As seen in Table 2, Cronbach's alpha for this scale was high (.86). We created a new aggregated scale to measure culturally competent service practices by averaging the final nine items.

\section{Cultural competence: personnel practices}

We excluded seven of the original 16 items because they had inconsistent item-test $(<.74)$ and item-rest $(<.67)$ correlations. As shown in Table 2, the resulting nineitem scale had a high Cronbach's alpha (.86) and all items contributed in the same direction. As in the previous measures, these items were averaged to create a new aggregate measure.

\section{Climate for implementation of cultural competence}

As seen in Table 3, Cronbach's alpha for midlevel leaders' prioritization of implementing cultural competence was very high (.88). In addition, all items contributed in the same direction and had item-test and itemrest correlations greater than .57. Given this information and for ease of interpretation, we created a new measure by averaging our items representing promoted, rewarded, and expected culturally competence practices.

\section{Within- and between-group analyses}

We computed indexes of within- and between-program consistency of responses for the measure of program climate for implementation of cultural competence. We calculated $r_{\mathrm{WG}}$ values to assess within-program consistency and found an average $r_{\mathrm{WG}}$ of .72 (not reported in tables), indicating a high level of consistency of responses within programs. We calculated intraclass correlation coefficients and reviewed the eta-squared values to determine between-program differences of 68 . The intraclass correlation coefficient (type 1 indicates the proportion of total variance between programs, whereas eta squared indicates the proportion of total variation between programs $[68,72,76,77]$. Type 1 intraclass correlation coefficient values (.07 in this study) are typically less than .20 and usually smaller than eta- squared values [76] supporting that program membership contributed to the resulting estimates. The consistency in within-program responses and discrepancy in between-program variance justified aggregating individual-level responses to the program level on measures of climate for implementation of cultural competence. This program-level measure was included in the following cross-level analyses of relationships between individual-level and program-level variables.

\section{Path analysis: hypothesis testing}

Results from each of the three path regression analyses indicated that transformational leadership was indirectly associated with implementation of three culturally competent practice outcomes through climate for implementation of cultural competence. See Fig. 1. We describe the results of the path analysis based on the three study hypotheses.

We found support for hypothesis 1, which posited that transformational leadership would be positively and indirectly related to the implementation of culturally competent knowledge through climate for implementation of cultural competence. Employees' and supervisors' higher ratings of their director's transformational leadership were indirectly associated with higher degree of implementation of culturally competent knowledge (standardized indirect effect $=.006$, bootstrap $p=.004$ ).

We found support for hypothesis 2 , which posited that transformational leadership would be positively and indirectly related to the implementation of culturally competent service practices through climate for implementation of cultural competence. Employees' and supervisors' higher ratings of their director's transformational leadership were indirectly associated with higher degree of implementation of service practices (standardized indirect effect $=.019$, bootstrap $p<.001$ ).

We found support for hypothesis 3 , which posited that transformational leadership would be positively and indirectly related to the implementation of culturally competent personnel practices through the role of climate for implementation of cultural competence. Employees' and supervisors' higher ratings of their director's transformational leadership were indirectly related to higher degree of implementation of culturally competent personnel practices (standardized indirect effect $=.014$, bootstrap $p=.005$ ). The main mediation models presented adequate fit statistics $\left(\chi^{2}=127.20, d f=22, p\right.$ $<.001$, RMSEA $<.001$, CFI $\approx 1.000$, TLI $\approx 1.000$ ).

Compared with the indirect relationships found, the analysis highlighted stronger direct relationships among variables of interest. Transformational leadership was positively associated with climate for implementation of cultural competence (standardized indirect effect $=.057$, bootstrap $p<.001)$. In particular, the relationship between 
climate for implementation of cultural competence and practices were robust-climate was positively associated with knowledge (standardized direct effect $=.103$, bootstrap $p=.025$ ), service practices (standardized direct effect $=.336$, bootstrap $p<.001$ ), and personnel practices (standardized direct effect $=.241$, bootstrap $p<.001$ ).

\section{Discussion}

The current study examined three areas: (a) exploration of a focused climate and development of an associated measure, climate for implementation of cultural competence; (b) development of culturally competent practices measures; and (c) examination of the model (relationships between leadership and these new measures). Findings highlight the importance of focused climates in maximizing the influence of transformational leadership on employees' implementation of congruent practices in health care. The measure representing climate for implementation of cultural competence had adequate psychometric properties and was further used to test a conceptual framework of the role of leadership in implementation processes in addiction health services organizations.

The culturally competent practices measures had adequate psychometric properties. The three measures (knowledge, services, and personnel practices) represented main areas of cultural competence in health care [3-5]. The examination of the relationships between leadership and these new program measures revealed associations among employee perceptions of executive or upper level directors leadership style, perceptions of middle managers' expectations, promotion, and rewards regarding the implementation of cultural competence (climate), and their reported implementation of increased knowledge about racial and ethnic minority communities, culturally tailored service practices, and culturally tailored personnel practices. We found that directors' transformational leadership influenced supervisors' expectations to implement cultural competence and that this cascading influence may affect implementation of congruent culturally responsive practices. These findings extend knowledge regarding the role of leadership and climate in the implementation process in health care.

\section{Theoretical implications}

Findings contribute to leadership theory on the embedded mechanisms that explain leadership influence on climate and practice implementation. Findings are consistent with emerging studies supporting the leadership-climate-practice mechanism in different organizational settings $[14,15$, 78]. Because few studies have investigated the leadership process of implementation of cultural competence, our primary contribution lies in developing a measure of climate for implementation of cultural competence and identifying its relationship with the implementation of three validated measures of culturally responsive practices.

At the core of the leadership process related to influencing followers' attitudes and behavior is the role of social exchange explained by social learning theory [79, 80]. However, additional embedded mechanisms play a role in influencing followers' attitudes and behaviors. For instance, the social learning model relies on transformational leaders' modeling behavior to emphasize principles (e.g., culture matters) and norms and behaviors (e.g., service providers should understand their clients' culture to serve them effectively). These principles and norms may influence followers including middle managers, who in turn play a critical role in developing and maintaining an organizational climate focused on implementation of cultural competence $[14,15]$.

By considering additional embedded mechanisms and players in the social exchange dynamics described in social learning theory, this study highlights the importance of considering the hierarchical and role functions of transformational (executive) leaders and middle managers. Transformational leaders promote growth and a common vision [21, 81]. However, middle managers may need to translate this vision into specific priorities, norms, and behaviors that are actionable at the employee level. Executive leaders may value culture, whereas middle managers prioritize employee cross-cultural training and employees build their knowledge of clients' cultural backgrounds and tailored service practices.

\section{Limitations and suggestions for future research}

We acknowledge that our data have several limitations that should be considered when interpreting our findings. We did not test causal or temporal relationships because we relied on cross-section data, but informed by a conceptual framework. Second, program measures were provided by an average of three staff members per program, not including more individuals to indicate greater agreement on program climate for implementation of cultural competence can be a limitation. However, these outpatient clinics are generally small, independent, and similar to doctor's offices. As such, these programs represent work environments that influence shared perceptions. We also acknowledge limitations on our measurement approach. We relied on individual respondent data and controlled for their nested structure instead of examining a true cross-level interaction relying only on measures separately aggregated at the counselor, supervisor, and director levels. Also, our measurement of climate for implementation, which relied on employees' perceptions of supervisors' priorities, or what is expected, rewarded, and promoted, needs to be further evaluated in terms of its discriminant validity. Emerging research has highlighted a strong 
relationship between middle managers' reported commitment to innovation and implementation effectiveness $[82,83]$. Distinguishing between middle-managers' selfreported commitment to implementation and employees' perceptions of their manager's expectations, rewards, and priorities is critical to identifying different mechanisms of implementation.

Finally, we consider a limitation measuring implementation based on staff members' reports of their program's delivery or use of culturally responsive practices, rather than directly observing practices being implemented. Nonetheless, we relied on large, multilevel data from employees nested in programs and measures featuring different scales. This last issue reduces common methods bias and improves the rigor of our analysis.

\section{Conclusions}

Findings underscore the empirical and theoretical importance of the leadership-climate relationship to implementing culturally competent practices in addiction health services. This is an important goal for these programs, which are located in one of the most ethnically diverse communities in the USA. Therefore, leadership development initiatives in health care can focus on teaching leaders to align incentives and communicate messages consistent with desired practices. Findings are relevant to executive leaders who may use a transformational leadership style (e.g., employee promotion) to influence midlevel supervisors' implementation expectations and priorities. By doing so, program leaders can establish an effective leadership-climate-practice approach in their programs that strategically aligns directors', supervisors', and employees' focus to enhance their organization's capacity to implement culturally competent services for racial and ethnic minority clients.

\section{Acknowledgements}

We appreciate the contributions of participants in the study. We also thank Veronica Serret and Tenie Khachikian for their support in summarizing data and Eric Lindberg for proofreading and editing the final draft.

\section{Funding}

Funding for the first author's role in this study was provided by a National Institute on Drug Abuse research grant (R33DA035634) and an implementation fellowship training grant (R25MH080916). This work was also supported by National Institute on Drug Abuse grant (R01DA038466) and National Institute of Mental Health grant (R01MH072961). The content is solely the responsibility of the authors and does not necessarily represent the official views of the National Institutes of Health.

\section{Availability of data and materials}

Please contact authors for data requests.

\section{Authors' contributions}

EG was the study principal investigator and developed the theoretical background and conceptualization of the study. KF developed the literature review, and YK contributed to the study design, writing, data analysis, and editing. All authors read and approved the final manuscript.
Ethics approval and consent to participate

This research was performed in accordance with the Declaration of Helsinki and approved by the Institutional Review Board at University of Southern California (No. UP-14-00105).

\section{Consent for publication}

Not applicable.

\section{Competing interests}

The authors declare that they have no competing interests.

\section{Publisher's Note}

Springer Nature remains neutral with regard to jurisdictional claims in published maps and institutional affiliations.

\section{Author details}

${ }^{1}$ Suzanne Dworak-Peck School of Social Work, University of Southern California, 655 West 34th Street, Los Angeles, CA 90089, USA. ${ }^{2}$ Marshall School of Business, University of Southern California, 655 West 34th Street, Los Angeles, CA 90089, USA. ${ }^{3}$ Mihaylo College of Business and Economics, California State University, Fullerton, Fullerton, CA 90089, USA.

Received: 25 January 2017 Accepted: 6 November 2017

Published online: 14 November 2017

\section{References}

1. Institute of Medicine. Crossing the quality chasm: a new health system for the twenty-first century. Washington, DC: National Academies Press; 2001.

2. Institute of Medicine. Unequal treatment: confronting racial and ethnic disparities in health care. Washington, DC: National Academies Press; 2013.

3. Betancourt JR, Green AR, Carrillo JE, Park ER. Cultural competence and health care disparities: key perspectives and trends. Health Aff. 2005;24: 499-505.

4. Brach C, Fraser I. Can cultural competency reduce racial and ethnic health disparities? A review and conceptual model. Med Care Res Rev. 2000; 57(suppl 1):181-217.

5. Harper M, Hernandez M, Nessman T, Mowery D, Worthington J, Issacs M. Organizational cultural competence: a review of assessment protocols. Tampa: University of South Florida, College of Behavioral and Community Sciences, Louis de la Parte Florida Mental Health Institute, Department of Child and Family Studies, Research and Training Center for Children's Mental Health; 2009.

6. Mason JL. Cultural competence self-assessment questionnaire: a manual for users. Portland: Portland State University, Research and Training Center on Family Support and Children's Mental Health; 1995.

7. Klein KJ, Sorra JS. The challenge of innovation implementation. Acad Manag Rev. 1996;21:1055-80.

8. Fiscella K, Franks P, Gold MR, Clancy CM. Inequality in quality. JAMA. 2000; 283:2579-84.

9. Becan JE, Knight DK, Flynn PM. Innovation adoption as facilitated by a change-oriented workplace. J Subst Abus Treat. 2012;42:169-78.

10. Guerrero EG, Garner BR, Cook B, Kong Y. Does the implementation of evidence-based and culturally competent practices reduce disparities in addiction treatment outcomes? Addict Behav. 2017;73:119-23.

11. Battilana J, Gilmartin M, Sengul M, Pache AC, Alexander JA. Leadership competencies for implementing planned organizational change. Leadersh Q. 2010;21:422-38.

12. Dinh JE, Lord RG, Gardner WL, Meuser JD, Liden RC, Hu J. Leadership theory and research in the new millennium: current theoretical trends and changing perspectives. Leadersh Q. 2014;25:36-62.

13. Zohar D. The effects of leadership dimensions, safety climate, and assigned priorities on minor injuries in work groups. J Organ Behav. 2002;23:75-92.

14. Zohar D. Safety climate: conceptualization, measurement, and improvement. In: Schneider B, Barbera KM, editors. The Oxford handbook of organizational climate and culture. New York: Oxford University Press; 2014. p. 317-34.

15. Schneider B, Ehrhart MG, Macey WH. Organizational climate and culture. Annu Rev Psychol. 2013;64:361-88.

16. Aarons GA, Ehrhart MG, Farahnak LR, Sklar M. Aligning leadership across systems and organizations to develop strategic climate for evidence-based practice implementation. Annu Rev Public Health. 2014;35:255-74. 
17. Judge TA, Piccolo RF. Transformational and transactional leadership: a metaanalytic test of their relative validity. J Appl Psychol. 2004;89:755-68.

18. Yukl G. Effective leadership behavior: what we know and what questions need more attention. Acad Manag Perspect. 2012;26(4):66-85.

19. Bass BM, Avolio BJ. Improving organizational effectiveness through transformational leadership. Thousand Oaks: Sage; 1994.

20. Piccolo RF, Bono JE, Heinitz K, Rowold J, Duehr E, Judge TA. The relative impact of complementary leader behaviors: which matter most? Leadersh Q. 2012;23:567-81.

21. Bass BM, Avolio BJ, Jung DI, Berson Y. Predicting unit performance by assessing transformational and transactional leadership. J Appl Psychol. 2003;88:207-18.

22. Edmondson AC. Managing the risk of learning: psychological safety in work teams. In: West MA, Tjosvold D, Smith KG, editors. International handbook of organizational teamwork and cooperative working. Chichester: Wiley; 2002. p. $255-75$.

23. Zhu W, Riggio RE, Avolio BJ, Sosik JJ. The effect of leadership on follower moral identity: does transformational/transactional style make a difference? J Leadersh Org Stud. 2011;18:150-63.

24. Aarons GA. Transformational and transactional leadership: association with attitudes toward evidence-based practice. Psychiatr Serv. 2006;57:1162-9.

25. Aarons GA, Sommerfeld DH. Leadership, innovation climate, and attitudes toward evidence-based practice during a statewide implementation. J Am Acad Child Adolesc Psychiatry. 2012;51:423-31.

26. D'Aunno T. The role of organization and management in substance abuse treatment: review and roadmap. J Subst Abus Treat. 2006;31:221-33.

27. May C. Towards a general theory of implementation. Implement Sci. 2013;8:18

28. Weiner BJ, Lewis MA, Linnan LA. Using organization theory to understand the determinants of effective implementation of worksite health promotion programs. Health Educ Res. 2009;24:292-305.

29. Dragoni L. Understanding the emergence of state goal orientation in organizational work groups: the role of leadership and multilevel climate perceptions. J Appl Psychol. 2005;90:1084-95.

30. Michaelis B, Stegmaier R, Sonntag K. Shedding light on followers' innovation implementation behavior: the role of transformational leadership, commitment to change, and climate for initiative. J Manag Psychol. 2010;25:408-29.

31. Schneider B. The climate for service: an application of the climate construct. In: Schneider B, editor. Organizational climate and culture. San Francisco: Jossey-Bass; 1990. p. 383-412.

32. Reichers AE, Schneider B. Climate and culture: an evolution of constructs. In: Schneider B, editor. Organizational climate and culture. San Francisco: Jossey-Bass; 1990. p. 5-39.

33. Schneider B. Organizational climates: an essay. Pers Psychol. 1975;28:447-79.

34. Jacobs SR, Weiner BJ, Bunger AC. Context matters: measuring implementation climate among individuals and groups. Implement Sci. 2014;9:46.

35. Zohar D. Thirty years of safety climate research: reflections and future directions. Accid Anal Prev. 2010;42:1517-22.

36. Ehrhart MG, Schneider B, Macey WH. Organizational climate and culture: an introduction to theory, research, and practice. New York: Routledge; 2014.

37. Schneider B, Ehrhart MG, Macey WH. Organizational climate research: achievements and the road ahead. In: Ashkanasy NM, Wilderom CPM, Peterson MF, editors. The handbook of organizational culture and climate. Thousand Oaks: Sage; 2011. p. 29-49.

38. Zohar D. A group-level model of safety climate: testing the effect of group climate on microaccidents in manufacturing jobs. J Appl Psychol. 2000;85: 587-96.

39. Beus JM, Payne SC, Bergman ME, Arthur W. Safety climate and injuries: an examination of theoretical and empirical relationships. J Appl Psychol. 2010; 95:713-27.

40. Johnson JW. Linking employee perceptions of service climate to customer satisfaction. Pers Psychol. 1996;49:831-51.

41. Hong $Y$, Liao $H, H u$ J, Jiang K. Missing link in the service profit chain: a meta-analytic review of the antecedents, consequences, and moderators of service climate. J Appl Psychol. 2013;98:237-67.

42. Hunter ST, Bedell KE, Mumford MD. Climate for creativity: a quantitative review. Creat Res J. 2007;19:69-90.

43. Scott SG, Bruce RA. Determinants of innovative behavior: a path model of individual innovation in the workplace. Acad Manag J. 1994;37:580-607.
44. Klein KJ, Knight AP. Innovation implementation: overcoming the challenge. Curr Dir Psychol Sci. 2005;14:243-6.

45. Klein KJ, Conn AB, Sorra JS. Implementing computerized technology: an organizational analysis. J Appl Psychol. 2001;86:811-24.

46. Holahan PJ, Aronson ZH, Jurkat MP, Schoorman FD. Implementing computer technology: a multiorganizational test of Klein and Sorra's model. J Eng Technol Manag. 2004;21:31-50.

47. Dong L, Neufeld DJ, Higgins C. Testing Klein and Sorra's innovation implementation model: an empirical examination. J Eng Technol Manag. 2008;25:237-55.

48. Ehrhart MG, Aarons GA, Farahnak LR. Assessing the organizational context for EBP implementation: the development and validity testing of the Implementation Climate Scale (ICS). Implement Sci. 2014;9:157.

49. Weiner BJ, Belden CM, Bergmire DM, Johnston M. The meaning and measurement of implementation climate. Implement Sci. 2011;6:78.

50. Bandura A. Social foundations of thought and action: a social-cognitive view. Englewood Cliffs: Prentice-Hall; 1986.

51. Berson Y, Avolio BJ. Transformational leadership and the dissemination of organizational goals: a case study of a telecommunication firm. Leadersh Q. 2004;15:625-46.

52. Chreim S, Williams BE, Coller KE. Radical change in healthcare organization: mapping transition between templates, enabling factors, and implementation processes. J Health Organ Manag. 2012;26:215-36.

53. Schein EA. Organizational culture and leadership. 2nd ed. San Francisco: Jossey-Bass; 1992.

54. Wimbush JC, Shepard JM. Toward an understanding of ethical climate: its relationship to ethical behavior and supervisory influence. J Bus Ethics. 1994; 13:637-47.

55. Zohar D. The influence of leadership and climate on occupational health and safety. In: Hofmann DA, Tetrick LE, editors. Health and safety in organizations: a multilevel perspective. San Francisco: Jossey-Bass; 2003. p. 201-30.

56. Zohar D, Luria G. Climate as a social-cognitive construction of supervisory safety practices: scripts as proxy of behavior patterns. J Appl Psychol. 2004; 89:322-33.

57. Aarons GA, Ehrhart MG, Farahnak LR. The implementation leadership scale (ILS): development of a brief measure of unit level implementation leadership. Implement Sci. 2014:9:45.

58. Jung DI, Chow C, Wu A. The role of transformational leadership in enhancing organizational innovation: hypotheses and some preliminary findings. Leadersh Q. 2003;14:525-44.

59. Carr JZ, Schmidt AM, Ford JK, DeShon RP. Climate perceptions matter: a meta-analytic path analysis relating molar climate, cognitive and affective states, and individual level work outcomes. J Appl Psychol. 2003;88:605-19.

60. Gil F, Rico R, Alcover CM, Barrasa Á. Change-oriented leadership, satisfaction and performance in work groups. J Manag Psychol. 2005;20:312-28.

61. Cohen J. Statistical power analysis for the behavioral sciences. 2nd ed. Hillsdale: Lawrence Erlbaum; 1988.

62. Broome KM, et al. Leadership, burnout, and job satisfaction in outpatient drug-free treatment programs. J Subst Abus Treat. 2009;37:160-70.

63. Guerrero EG. Enhancing access and retention in substance abuse treatment: the role of Medicaid payment acceptance and cultural competence. Drug Alcohol Depend. 2013:132:555-61.

64. Guerrero EG, Aarons GA, Palinkas LA. Organizational capacity for service integration in community-based addiction health services. Am J Public Health. 2014;104:e40-7.

65. Guerrero EG, He A, Kim A, Aarons GA. Organizational implementation of evidence-based substance abuse treatment in racial and ethnic minority communities. Adm Policy Ment Health Ment Health Serv Res. 2014;41:737-49.

66. Guerrero EG. Managerial capacity and adoption of culturally competent practices in outpatient substance abuse treatment organizations. J Subst Abus Treat. 2010:39:329-39.

67. Snijders TB, Bosker RR. Multilevel analysis: an introduction to basic and advanced multilevel modeling. Thousand Oaks: Sage; 1999.

68. Bryk AS, Raudenbush SW. Hierarchical linear models. Newbury Park: Sage; 1992.

69. Roman PM, Ducharme LJ, Knudsen HK. Patterns of organization and management in private and public substance abuse treatment programs. J Subst Abus Treat. 2006;31:235-43.

70. Allison PD. Missing data: quantitative applications in the social sciences. Br J Math Stat Psychol. 2002;55:193-6. 
71. Aarons GA, Sawitzky AC. Organizational culture and climate and mental health provider attitudes toward evidence-based practice. Psychol Serv. 2006;3:61-72.

72. Glisson C, James LR. The cross-level effects of culture and climate in human service teams. J Organ Behav. 2002;23:767-94.

73. James LR, Demaree RG, Wolf G. rwg: an assessment of within-group interrater agreement. J Appl Psychol. 1993;78:306-9.

74. Rentsch JR. Climate and culture: interaction and qualitative differences in organizational meanings. J Appl Psychol. 1990;75:668-81.

75. Hedeker D, Gibbons RD, Flay BR. Random-effects regression models for clustered data with an example from smoking prevention research. J Consult Clin Psychol. 1994;62:757-65.

76. Bliese PD. Within-group agreement, non-independence, and reliability: implications for data aggregation and analysis. In: Klein KJ, Kozlowski SW, editors. Multilevel theory, research, and methods in organizations. San Francisco: Jossey-Bass; 2000. p. 349-81.

77. Cohen J, Cohen P. Applied multiple regression/correlation analysis for the behavioral sciences. 2nd ed. Hillsdale: Lawrence Erlbaum; 1983.

78. Aarons GA, Ehrhart MG, Farahnak LR, Hurlburt MS. Leadership and organizational change for implementation (LOCI): a randomized mixed method pilot study of a leadership and organization development intervention for evidence-based practice implementation. Implement Sci. 2015;10:11.

79. Bass BM, Waldman DA, Avolio BJ, Bebb M. Transformational leadership and the falling dominoes effect. Group Org Manag. 1987;12:73-87.

80. Mayer DM, Kuenzi M, Greenbaum R, Bardes M, Salvador RB. How low does ethical leadership flow? Test of a trickle-down model. Organ Behav Hum Decis Process. 2009;108:1-13.

81. Avolio BJ, Gardner WL, Walumbwa FO, Luthans F, May DR. Unlocking the mask: a look at the process by which authentic leaders impact follower attitudes and behaviors. Leadersh Q. 2004;15:801-23.

82. Birken SA. Where the rubber meets the road: a mixed-method study of middle managers' role in innovation implementation in health care organizations. Chapel Hill: University of North Carolina at Chapel Hill; 2011.

83. Birken SA, Lee SY, Weiner BJ, Chin MH, Schaefer CT. Improving the effectiveness of health care innovation implementation: middle managers as change agents. Med Care Res Rev. 2013;70:29-45.

\section{Submit your next manuscript to BioMed Central and we will help you at every step:}

- We accept pre-submission inquiries

- Our selector tool helps you to find the most relevant journal

- We provide round the clock customer support

- Convenient online submission

- Thorough peer review

- Inclusion in PubMed and all major indexing services

- Maximum visibility for your research

Submit your manuscript at www.biomedcentral.com/submit

) Biomed Central 